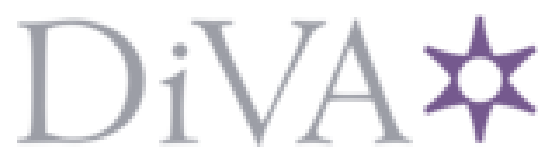

http://www.diva-portal.org

This is the published version of a paper published in African Safety Promotion: A Journal of Injury and Violence Prevention.

Citation for the original published paper (version of record):

Dalal, K., Jansson, B. (2007)

Cost calculation and economic analysis of violence in low-income country: a model for India.

African Safety Promotion: A Journal of Injury and Violence Prevention, 5(1): 45-56

http://dx.doi.org/10.4314/asp.v5i1.31633

Access to the published version may require subscription.

N.B. When citing this work, cite the original published paper.

Permanent link to this version:

http://urn.kb.se/resolve?urn=urn:nbn:se:oru:diva-41308 


\title{
COST CALCULATION AND ECONOMIC ANALYSIS OF VIOLENCE IN A LOW-INCOME COUNTRY: A MODEL FOR INDIA
}

\author{
Koustuv Dalal ${ }^{1}$, and Bjarne Jansson \\ Karolinska Institutet, Sweden
}

\begin{abstract}
Registry data on costs of injuries due to violence in low-income countries seldom cover the total burden imposed on the victim's family. An extended model was therefore developed, encompassing both socio-economic data and family characteristics. The model comprises 32 cost elements in four main categories: injury, death, deprivation and other costs. The main cost elements were income adjusted by family and years; income impact on the family; costs of physical, psychosocial and family deprivations, and cardinal approach of productivity loss. As a result of the five case studies performed in India, the supplementary variables contributed to a better understanding of the total burden on families. This adapted model could help to increase both validity and equality in household surveys. However, ethical issues related to the data collection procedure need to be considered and more empirical contributions from low-income countries in Africa, Asia and Latin America are warranted.
\end{abstract}

\section{INTRODUCTION}

Violence is one of the most expensive public health problems globally (Smith \& Barss, 1991; Desjarlais \& Kleinman, 1997; Krug, Dahlberg, Mercy, Zwi, \& Lozano, 2002; Krug, 2004a). Interpersonal and collective violence (war and conflicts) are mainly due to poverty, inequality, political instability and scarce resources (WHO, 2005). Low- and middle-income countries are over represented, and account for more than $90 \%$ of all violence-related deaths (WHO, 2004). Accordingly, cost calculation and economic analysis of violence, particularly in low-income countries,

1. Please direct all correspondence to Koustuv Dalal, Karolinska Institutet, Department of Public Health Science, Norrbacka, 2nd Floor, SE-171 76, Stockholm, Sweden; E-mail: koustuv.dalal@ki.se 
should become a prioritised task in the policy-making process (Khan, 2004; WHO, 2004). Additionally, health economists strongly advocate methodological improvements in the cost calculation of violence, with a particular emphasis on low-income countries (Conference Report, 2001).

Current reports on the costs of violence largely describe the situation in Western industrial countries (Krug, 2004b). There is a lack of models adapted to the situation in low-income countries (Waters, Hyder, Rajkotia, Basu, \& Butchart, 2005). When using registry data in cost calculations there is a lack of contextual information on family-income losses and intangible costs (Miller, 2001; WHO, 2004). In order to stimulate methodological development, a theoretical framework for low-income countries was launched, based on a literature review and focussing on validity problems in surveys of violence (Duvvury, Grown, \& Redner, 2004). It was recommended that surveys at household level, as a site of both production and reproduction, would better capture the implications for poverty, which are a key concern for low-income countries. However, several cost elements of importance to family-income losses during violent trauma have still not been explored. We, therefore, specifically address the problem of underestimation of costs due to violence in low-income countries. We have added a number of supplementary cost elements that focus on the economic impact of violence on the victim and the victim's family, including the cost of deprivation. Moreover, in most low-income countries there is almost no relevant registry data (Krug, 2004b). Consequently, case studies are recommended as at least a partial solution to the problem of context-dependent data (Morrison \& Orlando, 2004; WHO, 2004). Thus, there is a need to design and test models of the differing socioeconomic contexts of low-income countries in order to alleviate the problem of shortfalls in registry data and to narrow the violence-related underestimation gaps in the cost calculation of violence. In this study, we introduce and test a model that includes supplementary cost elements targeting the specific socio-economic characteristics of low-income countries that are applicable to household surveys.

\section{MATERIAL AND METHODS}

\section{Study area}

To a large extent, India has socio-economic and cultural features similar to other low-income countries, where both government and private healthcare facilities co-exist (Bhatia, 2005). Our model was tested in West Bengal and Andhra Pradesh in India during the year 2002. West Bengal is the state with the highest population density in India, and has typical Indian socio-economic and family characteristics. In order to consider these tribal, socio-economic and family aspects, we selected cases from the Andhra Pradesh area; the other cases were selected from both rural villages and urban areas in West Bengal.

\section{Selection strategy}

First, we performed a media survey of interpersonal and collective violence in India, and tried to identify the types of incidents with the highest frequencies, based solely on police reports. Except for police reports, there was no other information available on acts of violence. When identifying types of cases, many victims were included, but due to a high refusal rate only five were interviewed. 


\section{Development of the model}

According to Miller (2001), cost calculations should meet seven basic criteria:

- to draw problem size and risk assessment;

- to advocate on health and safety;

- to make sectoral comparisons for broad priority-setting;

- to budget injury prevention for resource allocation;

- to analyse prospective legislation and regulation;

- to evaluate the programme;

- to analyse cost-effectiveness.

We utilised the first four of these criteria.

Violence is typologically divided into three broad headings, namely: self-directed violence, interpersonal violence, and collective violence (WHO, 2002). Interpersonal violence consists of family and intimate-partner violence, which usually takes place in the home environment, while collective violence generally takes place outside the home (WHO, 2005). We have excluded self-directed violence from our model.

Initially, we formulated and tested a preliminary model, and presented the results at an international conference (Conference Report, 2001). Thereafter, we divided our data into the following four categories: Injury, Death, Deprivation and Other costs, which make up the IDDO model.

\section{INJURY COSTS}

There are recommendations concerning which elements should be included in costs associated with injury treatment (Haddix, Teutsch, \& Corso, 2003). However, these elements can only be effectively estimated when all relevant data are available. For low-income countries, where we lack sources, we suggest that the following elements be included in the calculation of injury costs.

\section{Medical costs}

There are some established methods for calculating medical costs (Haddix et al., 2003; Bowman, 2002; Miller, 2000). Generally, the medical payment system and the hospitals follow the diagnosticrelated group (DRG) system. However, as only a few private hospitals use the DRG system in India, we suggest that medical costs be calculated according to the following elements and methods.

\section{a. Basic Costs (BC)}

Depending on the degree of severity, medical practitioners define a victim's injury as minor, moderate or severe. Accordingly, we use the following cost elements: Basic Minor Injury Cost (BC1), Basic Moderate Injury Cost (BC2), and Basic Severe Injury Cost (BC3). Victims have access to government-provided healthcare facilities in hospitals, rural health centres or mobile medical units. The government funds the salaries of hospital staff (for physician services, nursing services, technical services and services at lower level, so-called Group-D staff), the expenses for some basic medicines, life-saving drugs, laboratory materials, costs of electricity, stationery, machinery and administration, and various other costs incurred by most established hospitals. 
The total expenditure of a government-run hospital is extracted from these expenses annually. From the in-patient record system we obtained the number of patients treated for each type of injury. Based on these data, we calculated the costs of $\mathrm{BC} 1, \mathrm{BC} 2$ and $\mathrm{BC} 3$ on a proportional basis.

Where a government-provided healthcare system is not available or not used by the victim, we have to consider other cost elements. The literature suggests that, in low-income countries, the majority of victims of violence prefer household or non-hospital based treatment (Varatharajan, 1999). In our study, if the victim did not use government-provided treatment, we interviewed victims or their relatives and asked them about the total amount they had paid for treatment in a private hospital.

\section{b. Other Treatment Costs (OTC)}

There are extra medical costs in India, as in most low-income countries. Nowadays, governments provide public medical facilities with hospital beds and services, albeit limited, from doctors and nurses. But the victim has to bear many extra costs, namely, Medical Drugs (M), Medical Instruments (I), Laboratory Diagnoses (D), and Paramedical (PM) services. Where healthcare services are fully privatised, the victim has to bear the Total Medical Bill (B) "out of pocket". After being discharged from hospital the victim may have to return for medical follow up, thus incurring what we call Medical Re-examination Costs (MREC).

In rural areas, where public healthcare facilities are least accessible, victims use available traditional treatments, which carry no cost. The local treatment providers have no medical education. They use only natural traditional treatments, with herbs and shrubs. If the victim receives such treatment, then we should consider the Local Treatment Cost (LTC).

\section{c. Transport Costs (TC)}

Transport by ambulance to a hospital from the injury scene gives rise to a Primary Ambulance Cost (PAC). When a patient is moved from a government hospital to a private hospital, or vice versa, there is a Secondary ambulance cost (SAC). The patient has to pay for both types of transport. Further medical examinations during rehabilitation also give rise to transport expenses, which we call the Medical re-examination transport cost (MRTC). The transport costs (PAC, SAC and MRTC) should be calculated on the basis of total kilometres travelled, multiplied by the present market rate of each kilometre travelled, i.e. PAC/SAC/CTC $=\mathrm{km}$ travelled $x$ travel cost per $\mathrm{km}$.

\section{d. Productivity Costs (PC)}

In low-income countries, families are usually dependent on one person's income. If the family breadwinner sustains an injury, the whole family is in a vulnerable economic position. During the victim's rehabilitation period the affected family suffers several socio-economic problems. Most females in India are engaged in household work, which is not included in national income accounting. Seasonal unemployment or disguised unemployment and underemployment are notable features of a low-income country. There is evidence that people with these kinds of economic vulnerability are more disposed to violence, and hence are more susceptible to violence-related injury (WHO, 2005). It is difficult to analyse the actual production losses of the underemployed or unemployed and household workers from violence-related injury (Miller, 2001). Here, we have a socio-economic setup where a high proportion of citizens are illiterate and live below the poverty line, and most people 
survive on one person's income. We propose the following measure of the economic impact on the victim's family of production losses: Income Adjusted by Family and Years (IAFY).

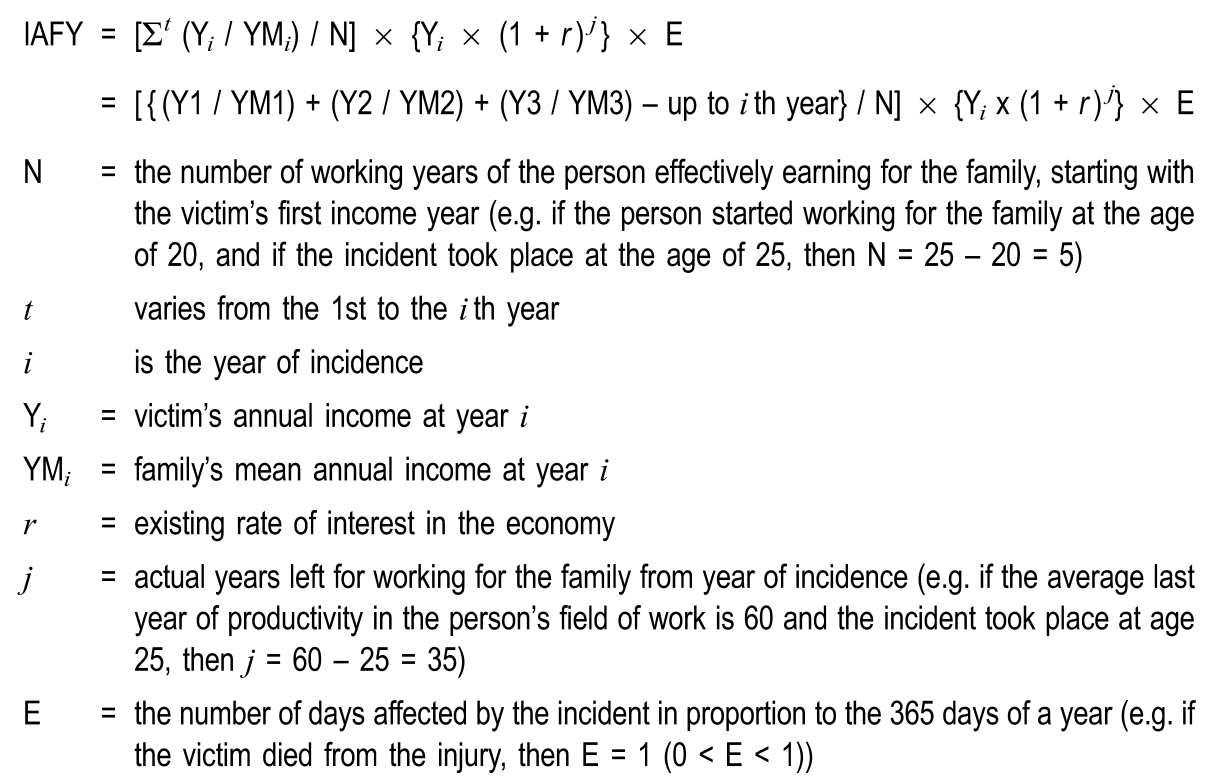

We should also consider that the average last productivity year varies according to sector (organised, unorganised, household, etc.).

Adopting the cardinal approach, we conducted a field study to find out the opportunity cost of household work (i.e. in relation to the next best alternative). We suggest that the opportunity cost per month in metropolitan areas is 2,100 INR per month (48 USD), in small towns and accessible villages 1,500 INR (34 USD), and in rural areas 800 INR (18 USD), excluding foodstuffs and fibres.

Through the IAFY calculation we considered the productivity costs of the injured person for one day, and then for the specific period. The variations are calculated on an average basis. Where applicable, the IAFY must be calculated on the basis of the actual number of days. If the IAFY calculation is confined to a specific period, where the addition of $Y / Y M$ over years is not necessary, then we should not divide it by $\mathrm{N}$. (That is, we should not re-average when we already have the average income of the injured person and their family.)

\section{DEATH COSTS}

For fatal injuries due to violence, the Medical Cost (MC) in India is zero. But if a person is admitted to hospital, then all the cost elements described above (under injury costs) are involved. After the death of the victim the following element should be added: the cost of last rituals, such as burial rites or funerals. Since this is a huge expenditure in some religions, we suggest the inclusion of the Ritual Cost (RC). 
If the victim is the family's main breadwinner, then their death has a huge economic impact on the family. This is estimated as the Income Impact on the Family (IIF).

$$
\begin{aligned}
\text { IIF } & =\left\{1-Y_{i} /\left(Y_{i}+Y_{t}\right)\right\} \times \operatorname{IAFY} \\
Y_{t} \quad= & j \times Y_{i}, \text { i.e. the years left in the person's working life, multiplied by the income earned in } \\
& \text { their last year. }
\end{aligned}
$$

\section{DEPRIVATION COSTS}

We suggest the following elements to measure the intangible costs of injury. A victim of violence suffers three types of deprivation, namely, physical deprivation, psychosocial deprivation, and family deprivation. When we calculate costs in our model, we consider the productivity and, hence, income losses from these three conditions. This is different from what we discussed as productivity cost (under injury costs above). After an injury event there is an immediate loss of production, which we incorporate into the IAFY. When the victim is declared medically fit, they will resume work. However, victims in moderate or severe cases will not be able to resume work at their previous level. We use the following concepts to calculate intangible effects.

\section{a. Cost of Physical Deprivation (CPD)}

After rehabilitation the victim will resume their work, but not necessarily at the same level. Suppose $\mathrm{T} 1$ is the date of the incident and $\mathrm{T} 2$ is the date of resumption of work. We should look at the daily average income $(\mathrm{Y} 1)$ for the three months before $\mathrm{T} 1$. We have to consider employment, seasonal employment and cyclical employment in the society in question.

$$
\left.\mathrm{CPD}=\left\{\Sigma\left(\mathrm{Y}_{i}-\mathrm{Y} 1\right) / 90\right)\right\} \times \mathrm{Dnl}
$$

$\left.\left\{\Sigma\left(Y_{i}-Y 1\right) / 90\right)\right\}$ is the mean deviation from $Y 1$ for daily income after T2 for the next three months. The limit after T2, the date of resumption of work, may be adjusted for more than three months, i.e. more than 90 days, if required.

\section{b. Cost of Psychosocial Deprivation (CPSD)}

The psychosocial effects on the victim's family income are measured using the following methods. Victims from an organised sector may have insurance (LIC). We suggest estimating the value of a statistical life we can calculate for permanent disability. Accordingly, an average of the insurance on a daily basis can be multiplied by the number of days of loss of production (Dnl).

$$
\text { CPSD }=\{\text { LIC / }(\mathrm{N} 1 \times 365)\} \times \mathrm{Dnl}
$$

$\mathrm{N} 1$ is the average last year of productivity in the person's field of work.

\section{c. Cardinal Approach of Productivity Loss (L)}

An alternative is to adopt the Cardinal Approach of Productivity Loss (L). Data are collected by interviews based on a protocol for losses due to psychosocial deprivation. In order to reduce bias and 
to obtain more accurate values, we suggest collecting $L$ in three different time periods in a week (say, $L 1, L 2$ and $L 3$ ), and then computing an average $L$. The average loss is multiplied by the number of days lost (Dnl).

$$
L=\{(L 1+L 2+L 3) / 3\} \times D n l
$$

For persons from the organised sector we use the CPSD, and for other cases we adopt L.

\section{d. Cost of Family Deprivation (CFD)}

In cases where the injury has an impact on the victim's family income, the Cost of Family Deprivation (CFD) should be calculated as follows.

$$
\mathrm{CFD}=\mathrm{IAFY} \times(\mathrm{L} / \mathrm{Dnl})
$$

\section{OTHER COSTS}

As well as the elements of injury costs, death costs and deprivation costs, violent incidents give rise to other costs. In some cases, the victim may lose personal durable and non-durable assets. The current Cost of Asset Lost (CAL) should be included. Material costs include Cost of Property Loss (CPL). Costs for hospital visits by family members should include Additional Transport Cost (ATC). These costs should be calculated in the same manner as for the PAC, SAC and MRTC.

An additional Food Cost for special food during rehabilitation should be included (AFC), as well as costs for the accident Insurance Premium (IP). If the victim's relatives have vowed an offering to a deity, which is very common in low-income countries, then allowance should be made for some Expenditure on Deity (ED). Then, we have to consider the Cost of Lost Income of Relatives or other concerned persons (ILC) who were not able to attend their regular work due to taking care of the victim.

For the whole incident there are some Preventive and/or Legal Costs (LC), which include the Police/ Moraal Cost (PolC). In the remotest rural areas, where police are not available, we should consider the Moraal (village leader) Cost (subsumed under PoIC), Paramilitary Cost (PMC), and Publicity Cost (PubC). In some cases of community/collective violence, the authority concerned might invest in some preventive publicity, which should be considered as a publicity cost. The PoIC or PMC can be calculated on a total hourly basis, namely, as the hours of involvement in the incident of various officers multiplied by their hourly salaries.

$$
L C=P o l C+P M C+P u b C
$$

We also consider the transport cost of preventive agents, namely, the Preventive Transport Cost (PTC $=\mathrm{km}$ travelled $\times$ cost per $\mathrm{km}$ travel), and the Judicial Costs (JC).

We collected and used the costs of each element under the medical costs and other costs headings. Other values of the variables under the productivity costs, death costs and deprivation costs headings were collected (important values are mentioned in the Results section for each case presented below (cases I to $\mathrm{V}$ ) and used in the formulae. The final values were derived from these formulae. 


\section{RESULTS}

The model was tested on five cases (see Table 1). Initially the calculations were based on Indian Rupees (INR), which were then converted into US Dollars (1 USD $=43.50$ INR).

- Case I: In a small town, a 32-year-old man, engaged in private tuition, was severely beaten by hooligans and sustained a skull fracture. His monthly income was 750 INR (17 USD). The monthly family income was 4,000 INR (92 USD). He was confined to his home, and could not work for one month.

- Case II: In Kolkata, a 9-year-old maid/servant from a nearby slum was brutally beaten by her employer and suffered a radial-bone fracture to her right arm. Her monthly income was 300 INR (7 USD) and the monthly family income was 1,200 INR (28 USD). Her recovery period was two months, after which she joined another household at 400 INR (9 USD) per month.

- Case III: In an urban area, a 50-year-old man was shot in the chest with a small gun by some miscreants. Two days later, he died in hospital. He was a labourer on a weekly wage, with a monthly income of 1,800 INR (41 USD) and with a monthly family income of 2,000 INR (46 USD).

- Case IV: Due to a dowry problem, a 27-year-old housewife was set on fire by members of her husband's family. She survived, but with severe burn injuries. The period of recovery was seven months. Her husband's monthly family income was 30,000 INR (690 USD), while the opportunity cost to her was 2,100 INR (48 USD).

- Case V: A 35-year-old tribe member was brutally injured on the buttocks with an ancient weapon. He was a seasonally unemployed person with an annual income of 5,000 INR (115 USD), while his annual family income was 11,000 INR (253 USD). He availed of the services of a local treatment provider and resumed work after three months.

Table 1. Costs of violence in five cases based on four categories: Injury, Death, Deprivation and Other costs in India, 2002-2003 in USD.

\begin{tabular}{|l|c|c|c|c|c|}
\hline Cost elements & Case I & Case II & Case III & Case IV & Case V \\
\hline $\begin{array}{l}\text { INJURY COSTS } \\
\text { Medical Costs }\end{array}$ & 1.84 & & & & \\
\hline Basic Minor Injury Cost (BC1) & & 10.34 & & & \\
\hline Basic Major Injury Cost (BC2) & & & 96.55 & & \\
\hline Basic Severe Injury Cost (BC3) & 34.25 & 20.18 & 6.16 & 201.49 & \\
\hline Medical Drugs (M) & 0.23 & 5.98 & 0.64 & 103.45 & \\
\hline Medical Instruments (I) & & 3.68 & 2.07 & 112.64 & \\
\hline Laboratory Diagnoses (D) & & & & 82.76 & \\
\hline Paramedical (PM) & & 1.15 & & 40.23 & \\
\hline Medical Re-examination Cost (MREC) & & & & 1054.7 & \\
\hline Total Medical Bill: Private Hospital (B) & & & & 1 & \\
\hline
\end{tabular}




\begin{tabular}{|c|c|c|c|c|c|}
\hline Cost elements & Case I & Case II & Case III & Case IV & Case V \\
\hline Local Treatment Cost (LTC) & & & & & 59.77 \\
\hline Primary Ambulance Cost (PAC) & 1.61 & 2.41 & 5.75 & 5.75 & \\
\hline Secondary Ambulance Cost (SAC) & & & & 17.24 & \\
\hline $\begin{array}{l}\text { Medical Re-examination Transport Cost } \\
\text { (MRTC) }\end{array}$ & 0.69 & 0.46 & & 25.29 & \\
\hline \multicolumn{6}{|l|}{ Productivity Costs } \\
\hline $\begin{array}{l}\text { Income Adjusted by Family and Years } \\
\text { (IAFY) }\end{array}$ & 18.83 & 85.70 & 1043.95 & 181.98 & 62.71 \\
\hline \multicolumn{6}{|l|}{ DEATH COSTS } \\
\hline Ritual Cost (RC) & & & 206.90 & & \\
\hline Income Impact on the Family (IIF) & & & 969.38 & & \\
\hline \multicolumn{6}{|l|}{ DEPRIVATION COSTS } \\
\hline Cost of Physical Deprivation (CPD) & & -4.60 & & 293.79 & 20.92 \\
\hline Cost of Psychosocial Deprivation (CPSD) & & & & 21.63 & \\
\hline Cardinal Approach of Productivity Loss (L) & & & & & 41.38 \\
\hline Cost of Family Deprivation (CFD) & & & & & 42.80 \\
\hline \multicolumn{6}{|l|}{ OTHER COSTS } \\
\hline Cost of Asset Loss (CAL) & & & & & 8.18 \\
\hline \multicolumn{6}{|l|}{ Cost of Property Loss (CPL) } \\
\hline Additional Transport Cost (ATC) & 2.53 & 2.07 & & 124.14 & \\
\hline Additional Food Cost (AFC) & 1.38 & 0.46 & & & \\
\hline Insurance Premium (IP) & & & & 163.49 & \\
\hline Expenditure on Deity (ED) & 4.60 & 0.23 & 0.69 & 23.01 & 4.05 \\
\hline Cost of Lost Income of Relatives (ILC) & 8.28 & 3.45 & 2.76 & 193.10 & \\
\hline \multicolumn{6}{|l|}{ Preventive and/or Legal Costs } \\
\hline Police/Moraal Cost (PolC) & 7.17 & & 199.31 & 53.66 & 16.09 \\
\hline Paramilitary Cost (PMC) & & & 0.00 & 149.43 & \\
\hline Publicity Cost (PubC) & & & 7.13 & 13.79 & \\
\hline Preventive Transport Cost (PTC) & & & 41.38 & 73.56 & \\
\hline Judicial Cost (JC) & 4.97 & & 135.40 & & \\
\hline TOTAL COSTS (USD) = & 87 & 132 & 2719 & 2935 & 256 \\
\hline
\end{tabular}


Total costs of the violence are estimated as follows:

Case I - 3,785 INR (87 USD);

Case II - 5,742 INR (132 USD);

Case III - 118,277 INR (2,719 USD);

Case IV - 84,173 INR (1,935 USD); and

Case V - 11,136 INR (256 USD).

These costs reflect all possible calculable factors; they are dependent upon the intensity of the violence and socio-economic position of the victim.

\section{DISCUSSION}

From the literature it is evident that calculations of injury costs vary considerably, mainly as a result of differences in methodology and selection of cost elements (Duvvury, Grown, \& Redner, 2004). Also, calculating economic losses based solely on foregone wages and income has a tendency to understate the losses in low-income countries (Waters et al., 2005). Many low-income countries lack reliable data, and very few countries collect information on violence on a regular basis. There is differential access to registry data and differences in economic and family structure between highincome and low-income countries. We, therefore, tried to explore the specific economic impact of violence on the victim and the victim's family in a low-income country, including costs of deprivation.

We observed that the IAFY cost element, which was introduced to consider the impact on the family had, overall, a significantly larger value than the victim's monthly income. For example, in Case I the victim's monthly income was 17 USD, compared with a total impact of 37 USD on the family. Also, in Case III, the IAFY and IIF estimated together came to 2,013 USD, compared with the victim's monthly income of 41 USD. So, the impact on the family can be much greater than when only the breadwinner's income is considered. This aspect, however, needs to be studied among a representative sample of families at risk.

Researchers have advocated three different types of methodologies to measure direct and indirect costs: proportional, econometric, and accounting (Duvvury et al., 2004). We used proportional methods to calculate medical costs. To calculate monetary values of productivity and deprivation costs we used economic and mathematical analysis. Other costs, for example, transport costs and private hospital bills, were estimated using accounting methods. Accordingly, our results are based on procedures that follow previous research recommendations.

Our model meets the four basic criteria of cost calculations presented by Miller (2001). In line with the first criterion on problem size, we estimated the total economic burden of violence on victims and their families by using cost elements in the following categories: injury, death, deprivation and other costs. In a macro setting, our model enables the total costs of violence in an area for a certain period to be estimated. We believe that the estimated costs can be used for resource allocation and as a basis for setting priorities with regard to safety and violence prevention.

The majority of existing studies have estimated the costs of interpersonal violence in specific sectors, 
focusing on direct medical costs (Mansingh \& Rampal, 1993; Wisner, Gilmer, Saltzman, \& Zink, 1999), health costs (Day, 1995; Rudman \& Davey, 2000) and economic output losses for employer and employee (Walby, 2004). However, these studies mainly concern high-income countries. By contrast, our study focuses predominantly on the economic impact of violence on victims' families in the light of family characteristics in a low-income country. There was, however, the limitation that due to an absence of baseline registry data concerning Indian government-run hospitals - it was difficult to calculate medical costs. Other crucial limitations lay in refusal to participate and recall bias among respondents (victims and relatives). The collection of data at individual level in the study area was hampered by two sensitive issues, namely, violence itself and economic affairs within the families. The victims and their family members were not fully prepared to share information with the interviewers. Experiences from other household surveys reveal that families are more inclined to share information than lone respondents (Duvvury, et al., 2004). Thus, the model employed needs to be tested among households in India using established survey methods.

This is a pilot study, which tries to explore the cost of violence in a low-income country. The model employed is limited in that it is only concerned with the calculation of the costs of interpersonal and collective violence (not self-directed violence). Nevertheless, it should be seen as representing a step towards developing an instrument adapted to the specific prerequisites of low-income countries. Further, the model needs to be tested in other parts of the world with the same problem of lack of registry data, for example, Asia, Africa and Latin America.

\section{REFERENCES}

Bhatia, P. (2005). Health Insurance in India. Retrieved November 25, 2005, from http://www.pitt.edu/ super1/ lecture/lec19571/index.htm.

Bowman, B. (2002). Towards a South African injury costing model: A review of the literature for development of a process path. African Safety Promotion: A Journal of Injury and Violence Prevention, 1(1), 55-64.

Conference Report. (2001). 1st Safe Community Conference on Cost Calculation and Cost-Effectiveness in Injury Prevention and Safety Promotion, Viborg County, Denmark, September 30 to October 3, 2001.

Day, T. (1995). The health related costs of violence against women in Canada. London, Ontario: Centre for research on violence against women and children.

Desjarlais, R., \& Kleinman, A. (1997). Violence and well-being. Social Science and Medicine, 45(8), 11431145.

Duvvury, N., Grown, C., \& Redner J. (2004). Costs of intimate partner violence at the household and community level. An operational framework for developing countries. Retrieved March 5, 2007, from http:/l www.icrw.org/docs/2004_paper_costingviolence.pdf.

Haddix, A.C., Teutsch, S.M., \& Corso, P.S. (Eds.). (2003). Prevention effectiveness a guide to decision analysis and economic evaluation. New York: Oxford University Press.

Khan, A. (2004). WHO argues the economic case for tackling violence. The Lancet, 363(9426), 2058.

Krug, E. (2004a). World Health Assembly resolutions on violence and injury prevention: New opportunities for national action. Injury Control and Safety Promotion, 11(4), 259-263. 
Krug, E. (2004b). Injury surveillance is key to preventing injuries. The Lancet, 364 (9445), 1563-1566.

Krug, E., Dahlberg, L., Mercy, J., Zwi, A., \& Lozano, R. (2002). World report on violence and health. WHO: Geneva.

Mansingh, A., \& Rampal, A. (1993). The nature of interpersonal violence in Jamaica. West Indian Medical Journal, 42, 53-56.

Miller, T. (2000). Assessing the burden of injury: Progress and pitfalls. In D. Mohan \& G. Tiwari (Eds.), Injury Prevention and Control (pp.49-70). London: Taylor and Francis.

Miller, T. (2001). Computing and presenting injury costs. Conference report. $1^{\text {st }}$ Safe Community Conference on Cost Calculation and Cost-Effectiveness in Injury Prevention and Safety Promotion, Viborg County, Denmark, September 30 to October 3, 2001.

Morrison, A., \& Orlando, M. (2004). The costs and impacts of gender-based violence in developing countries: Methodological considerations and new evidence. Retrieved March 05, 2007, from http://siteresources.worldbank.org/INTGENDER/Resources/costsandimpactsofgbv.pdf.

Rudman, W., \& Davey, D. (2000). Identifying domestic violence within inpatient hospital admissions using medical records. Women Health, 30(4), 1-13.

Smith, G., \& Barss, P. (1991). Unintentional injuries in developing countries: The epidemiology of a neglected problem. Epidemiologic Review, 13, 228-266.

Varatharajan, D. (1999). Improving the efficiency of public health care units in Tamil Nadu, India. Retrieved March 5, 2007, from http://www.hsph.harvard.edu/takemi/rp165.pdf.

Walby, S. (2004). The cost of domestic violence. United Kingdom, Women and Equality Unit: Department of Trade and Industry.

Waters, H., Hyder, A., Rajkotia, Y., Basu, S., \& Butchart, A. (2005). The costs of interpersonal violence - an international review. Health Policy, 73, 303315.

Wisner, C., Gilmer, T., Saltzman, L, \& Zink, T. (1999). Intimate partner violence against women: Do victims cost health plans more. The Journal of Family Practice, 48(6), 439-443.

World Health Organization (WHO). (2002). World report on violence and health. Geneva: WHO.

World Health Organization (WHO). (2004). The economic dimensions of interpersonal violence. Department of injuries and violence prevention: Geneva.

World Health Organization (WHO). (2005). Violence Prevention Alliance: Building global commitment for violence prevention. Geneva: WHO. 